\title{
Investigation and Modeling of the Degradation of Zr-Based Fuel Claddings during Corrosion in Steam and Air-Steam Mixtures at High Temperatures
}

\author{
Florian Haurais (florian.haurais@edf.fr) ${ }^{1,3}$ \\ Émilie Beuzet ${ }^{1}$ \\ Martin Steinbrïck ${ }^{2}$ \\ Éric Simoni ${ }^{3}$ \\ Antoine Ambard 4 \\ Mohamed Torkhani ${ }^{1}$
}

${ }^{1}$ EDF R\&D, Département SINETICS, 91120 Palaiseau, France

2 Karlsruhe Institute of Technology, Institute for Applied Materials, 76344 EggensteinLeopoldshafen, Germany

${ }^{3}$ Institut de Physique Nucléaire d'Orsay, CNRS-IN2P3, Univ. Paris-Sud, Université ParisSaclay, 91405 Orsay cedex, France

${ }^{4}$ EDF R\&D, Département MMC, 77250 Écuelles, France

\begin{abstract}
This paper presents the main results of a study conducted to quantify and to model the degradation state of $\mathrm{Zr}$-based fuel claddings submitted to severe accident conditions in a nuclear reactor core: high temperatures and either pure steam or air-steam mixture. Due to the progressive thickening of a dense and protective $\mathrm{ZrO}_{2}$ layer, the oxidation kinetics of $\mathrm{Zr}$-based claddings in steam at high temperatures typical of nuclear severe accidents, is generally cubic or parabolic. However, for some temperature domains, this oxide layer may crack, becoming porous and non-protective anymore. In these 'breakaway' conditions, the oxidation kinetics change from (sub-)parabolic to linear or even accelerated. Additionally, the temperature increase can lead core materials to melt and to relocate down to the vessel lower head, threatening its integrity. If it fails, and for specific conditions, air ingress may take place into the reactor. Hence, oxygen and nitrogen both react with $\mathrm{Zr}$-based claddings, successively through oxidation of $\mathrm{Zr}$ (forming $\mathrm{ZrO}_{2}$ layer), nitriding of $\mathrm{Zr}$ (forming $\mathrm{ZrN}$ particles) and oxidation of $\mathrm{ZrN}$ (forming $\mathrm{ZrO}_{2}$ and releasing nitrogen). These self-sustained chemical reactions enhance the deterioration of $\mathrm{Zr}$-based claddings and of their $\mathrm{ZrO}_{2}$ layers, inducing a rise of their open porosity. To quantify this porosity, a series of two-step experiments was conducted. First, ZIRLO ${ }^{\circledR}$ cladding samples were isothermally oxidized in various conditions: in pure steam or in 50$50 \mathrm{~mol} \%$ air-steam mix, at several temperatures, and for different durations. The main thermal effects on reaction kinetics and the high impact of air on the cladding degradation are all confirmed by experimental results. Second, pioneering porosimetry measurements by $\mathrm{Hg}$ intrusion were realized for the first time on such corroded cladding samples. In both atmospheres, it is pointed out that 1200 and
\end{abstract}


$1250 \mathrm{~K}$ lead to particularly porous oxide layers, especially due to strong 'breakaway' effects. Moreover, it is confirmed that the presence of air strongly enhances the oxide cracking: cladding samples are more porous when oxidized in the air-steam mixture than under pure steam. Finally, it is observed that in all conditions, the open porous volume fraction of ZIRLO ${ }^{\circledR}$ claddings continuously rises during their corrosion process. Hence, for each experimental condition, porosity correlations are determined through linear regressions, and porosity increase rates are deduced by derivation versus time and validated against porosimetry results of cladding samples corroded in transient (nonisothermal) conditions.

\title{
KEYWORDS
}

\author{
Nuclear Severe Accident \\ Zr-based fuel claddings \\ Thermochemical reactions \\ Degradation phenomena \\ Corrosion experiments \\ Porosimetry measurements \\ Porosity increase rates
}

\section{INTRODUCTION}

In Nuclear Power Plants (NPPs), a Severe Accident (SA) is a low likelihood sequence of events during which components of the reactor core get damaged.

In Pressurized Water Reactors (PWRs), a SA sequence is supposed to start with a breach of the primary circuit inducing a loss of cooling water. Thanks to the automatic drop of control rods, the reactor is shut down and the fission power reaches zero. However, in case of safety system failure(s) and/or human error(s), the decay power is not sufficiently removed, leading first to vaporization of water and then to exothermic oxidation by steam of core materials. The total heat from both decay and oxidation may induce a large temperature increase and so a progressive melting of central core components. Then, the molten material mixture called corium would continuously relocate down to the lower head of the reactor vessel, threatening its integrity. A vessel failure could in turn lead to air ingress from the containment into the reactor through a chimney effect. Consequently, air-steam mixtures could react with still solid peripheral core components [1,2].

The nuclear fuel cladding, made of zirconium alloys, is not only one of the main core components but also the first safety barrier of NPPs. It is then crucial to investigate and understand the behaviour of Zr-based fuel claddings, especially their chemical reactions and degradation processes during the different steps of a potential SA sequence, in order to correctly predict the hydrogen production and the radioactivity source term.

Among the experiments realized so far in this framework, many have been conducted at IRSN [3, 4], and at KIT where it consists of semi-integral QUENCH experiments and 
complementary small-scale Separate-Effects Tests (SET) [5]. The semi-integral tests show that the core coolability and the hydrogen production during a reflooding with water depend not only on the reflood flow characteristics (rate, area, position) and the temperature, but also on the degradation state of Zr-based claddings: their oxidation degree (oxide layer thickness) and their protectiveness (oxide layer density) [5, 6, 7]. The small-scale tests show that the degradation of $\mathrm{Zr}$-based claddings and especially their oxide layer characteristics depend on the experimental conditions: temperature, atmosphere and duration $[5,8,9,10]$.

Therefore, the oxide layer characteristics (thickness and density) are key parameters influenced by the corrosion conditions and influencing the SA progress. In practice, only the evolution of its thickness is quantitatively recorded during experiments and simulated in most of the SA codes through correlations. However, the evolution of its density, and hence of its protectiveness, is not experimentally recorded and not precisely simulated in SA codes in which oxide layers are considered as dense, without porosity. This could be a cause of underestimations by SA codes of oxidation enhancements and hydrogen productions observed during water reflooding tests $[11,12]$. Consequently, it was decided to measure the open porosity of oxidized Zr-based claddings [13, 14]. After a part describing the experimental facilities and test matrix (2), this paper presents the main results of two-step experiments: isothermal oxidation SET of Zr-based claddings in SA conditions (3), porosimetry by mercury intrusion of these corroded claddings (4), and determination of porosity increase rates through regressions and their validation against non-isothermal oxidation SET (5).

\section{EXPERIMENTAL FACILITIES AND TEST MATRIX}

This part first describes the experimental setup used to oxidize Zr-based claddings (2.1) and then justifies the test matrix that has been performed (2.2). Finally, it presents the experimental method and setup used to measure the porosity of the corroded samples (2.3).

\subsection{Experimental setup for corrosion tests}

The zirconium oxidation is associated with a mass increase because of the absorption of oxygen by the metal and the formation of zirconia $\mathrm{ZrO}_{2}$. The reaction rate of a $\mathrm{Zr}$-based sample is thus proportional with its mass gain rate. Consequently, the oxidation SET presented in this paper rely on the reaction of Zr-based cladding samples with oxidizing gases in the furnace of a thermobalance, which records the sample mass increase. This balance is coupled with a mass spectrometer, which records the outlet gas chemical composition, as schematized on Figure 1.

The test sequence starts at room temperature with the insertion of the cladding sample in the furnace. After closing, heaters increase the temperature, under inert argon gas, up to the desired value. When it is reached, 10 minutes are spent to stabilize it. Then, the pre-selected oxidizing gas flux is switched on during a pre-selected period. At the end, the gas flux and the heaters are switched off and the temperature decreases, in argon again. When a sufficiently low temperature is reached down, the oxidized $\mathrm{Zr}$-based cladding sample can be recovered. 
In the present study, the experimental setup used for corrosion tests was composed of a thermobalance $S T A-409$, from Netzsch, coupled with a quadrupole mass spectrometer Aeolos, from Netzsch too. Into this thermobalance, the steam supply is performed by a liquid mass flow controller from Bronkhorst ${ }^{\circledR}$ coupled with a Controlled Evaporator Mixer, while supplies of other gases are realized only by a mass flow controller, from Bronkhorst ${ }^{\circledR}$ too. The global reacting gas flow rate applied for this study was $0.278 \mathrm{~mol}^{-1} \mathrm{~h}^{-1}$ Additionally, 0.134 mol. $\mathrm{h}^{-1}$ of argon was continuously injected as inert carrier gas during all corrosion tests.

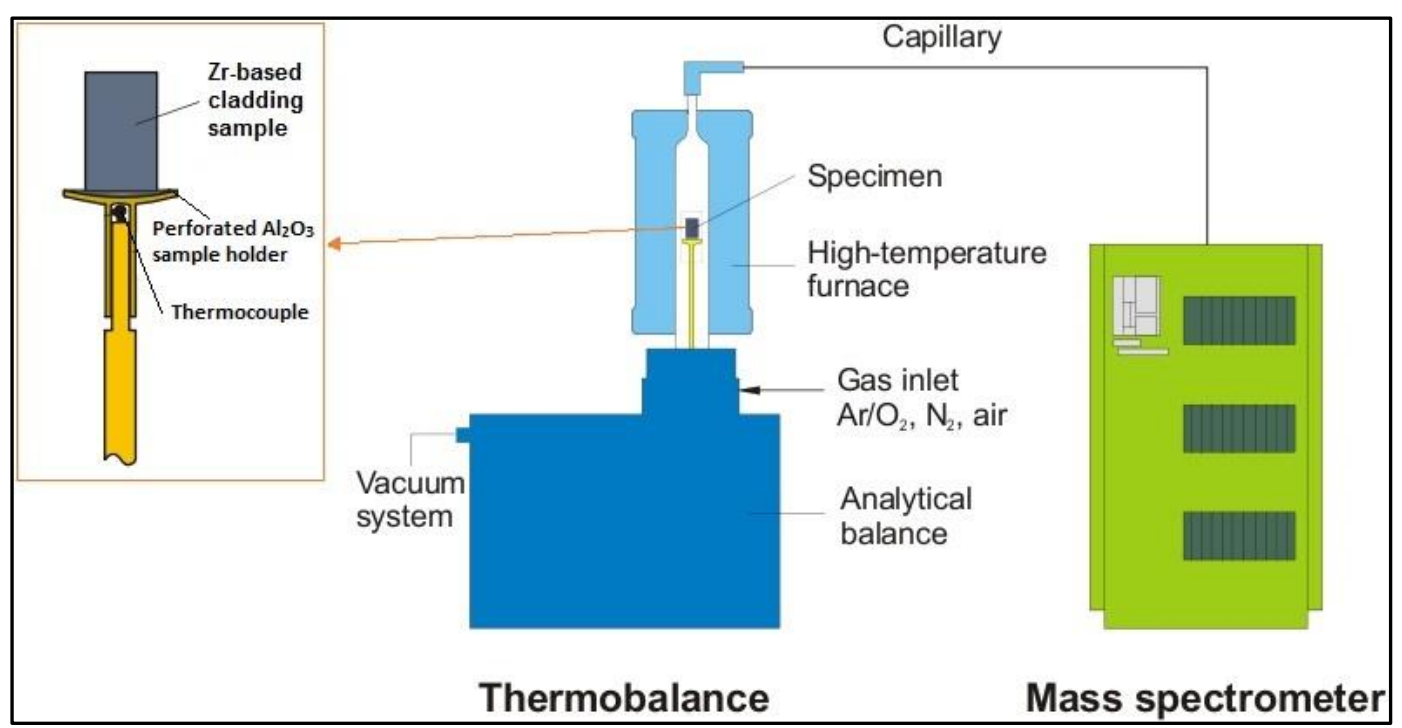

Figure 1: Scheme of the experimental setup used to perform corrosion tests

\subsection{Experimental test matrix}

The chosen $\mathrm{Zr}$ alloy was ZIRLO® from Westinghouse because it is one of the most widely used in PWRs. For this study, the cladding samples were $10 \mathrm{~mm}$-long tube segments, with PWRs-prototypical dimensions: thickness of $0.57 \mathrm{~mm}$ and external diameter of $9.50 \mathrm{~mm}$. They were cut from longer cladding tubes, then deburred and ground on both ends, and cleaned in an ultrasonic bath with acetone. During the oxidation SET, the samples were vertically positioned in the furnace of the thermobalance, on a perforated alumina sample holder used to avoid gas stagnations and/or starvations inside the tube segments.

As mentioned in the introduction, two main atmosphere types may exist in PWRs under SA conditions: pure steam and air-steam mixtures, respectively before and after a potential vessel failure with air ingress. Considering previous studies, it was chosen in this work to submit the cladding samples either to pure steam or to a 50-50mol\% air-steam mix. Moreover, in PWRs in SA conditions, a wide temperature range is possible, from $1000 \mathrm{~K}$ up to more than $2000 \mathrm{~K}$. Considering the limits of the experimental setup, it was decided for this study to perform isothermal corrosion tests from 1100 up to $1500 \mathrm{~K}$, in order to investigate the influence of the temperature on the characteristics (appearance and porosity) of the $\mathrm{ZrO}_{2}$ layers formed on the ZIRLO® samples. Additionally, it was decided to investigate influences of the 'breakaway' and of the oxidation degree on the oxide layer characteristics. Thus, in each experimental condition, several corrosion tests were performed with various durations, 
so that the 'breakaway': does not occur, has just occurred, or occurred a longer time ago (leading to cladding samples with final mass gains between 2 and $20 \mathrm{wt} \%$ ). Finally, in order to estimate the reproducibility of the applied porosimetry method, at least two experiments were performed in each experimental condition and for each duration.

\subsection{Experimental method and setup for porosimetries}

Many materials contain an open void volume which is called open porosity and distributed in the form of pores, cavities and cracks of various shapes and sizes. To characterize it, the most widely used experimental methods are porosimetry measurements by intrusion $[15,16]$ : they rely on the use of a non-wetting liquid penetrating into porous materials by pressure rises in a porosimeter. The pore diameter $\mathrm{D}_{\mathrm{P}}(\mathrm{m})$ is determined by $\mathrm{Eq}$. (1) as follows: [15, 17]

$$
D_{P}=\frac{4 \times \sigma \times \cos (\theta)}{P_{L}-P_{G}}
$$

$\sigma\left(\mathrm{N} \cdot \mathrm{m}^{-1}\right)$ and $\theta\left(^{\circ}\right)$ are the surface tension and the mean contact angle of the used liquid. $\mathrm{P}_{\mathrm{G}}\left(\mathrm{N} \cdot \mathrm{m}^{-2}\right)$ and $\mathrm{P}_{\mathrm{L}}\left(\mathrm{N} . \mathrm{m}^{-2}\right)$ are the pressures in the gas and in the intruding liquid. The most often employed liquid is mercury due to its highly non-wetting properties: $\sigma(\mathrm{Hg})=0.48 \mathrm{~N} . \mathrm{m}^{-1}$ and $\theta(\mathrm{Hg})=140^{\circ}$. Before starting a test, a relative vacuum is created in the porosimeter $\left(\mathrm{P}_{\mathrm{G}}=\right.$ 0), so that Eq. (1) becomes Eq. (2): [15, 17]

$$
D_{P}=\frac{1.47 N \cdot m^{-1}}{P_{L}}
$$

$\mathrm{P}_{\mathrm{G}}$ is then increased step by step because a short time period is systematically needed for the liquid $\mathrm{Hg}$ to fill the pores and for the equilibrium to be reached. The resulting $\mathrm{P}_{\mathrm{L}}$ changes and can be measured, so that it is possible among others to plot diameter and volume distributions of pores, to know the total porous volume of the material sample, to deduce its bulk and absolute densities, and to determine its porosity ratio $[15,16,17,18]$.

In the present study, the porosimeter (by $\mathrm{Hg}$ intrusion) was a twofold device fabricated by FISONS Instrument: a PASCAL 140 in which the pressure may rise from $100 \mathrm{~Pa}$ up to 400 $\mathrm{kPa}$ for pores bigger than $4 \mu \mathrm{m}$, and a PASCAL 440 in which the pressure may rise from 100 $\mathrm{kPa}$ up to $400 \mathrm{MPa}$ for pores bigger than $4 \mathrm{~nm}$. These porosimeters apply a special measurement technique consisting in a progressive pressurization with automatic and logical adjustments: the pressure increase accelerates up to a maximum value while pores are not detected, and decelerates down to a minimum value when pores are detected. This technique allows combining a relatively short analysis time with a high accuracy. $[16,17,18]$

\section{CORROSION OF ZIRLO® CLADDINGS AT HIGH TEMPERATURES}

In this part, the $\mathrm{Zr}$ corrosion phenomenology is described, and the results obtained with ZIRLO® cladding samples under pure steam (3.1) and in the air-steam mixture (3.2) are presented and analysed. 


\subsection{Phenomenology and results under pure steam}

At the beginning of a SA sequence, the non-removed decay heat induces a fast water vaporization and a strong oxidation of zirconium of the fuel claddings, according to Eq. (3):

$$
\mathrm{Zr}(\mathrm{s})+2 \mathrm{H}_{2} \mathrm{O}(\mathrm{g}) \stackrel{\Delta H=-600 \mathrm{~kJ} \cdot \mathrm{mol}^{-1}}{\longrightarrow} \mathrm{ZrO}_{2}(\mathrm{~s})+2 \mathrm{H}_{2}(\mathrm{~g})
$$

This exothermic reaction is detrimental for three reasons: it liberates additional heat, produces hydrogen and degrades properties of the Zr-based fuel claddings. This chemical reaction is quantified by the mass gain recording over the time: the Specific Mass Gain (SMG, absolute mass gain divided by sample surface) is proportional with the time to the power $1 / \mathrm{n}$ which corresponds to the kind of oxidation kinetics.

Due to the progressive thickening of a dense and protective $\mathrm{ZrO}_{2}$ layer, the oxidation kinetics of $\mathrm{Zr}$-based claddings is generally parabolic or cubic $(2<\mathrm{n}<3)$ under pure steam. However, due to the higher molar volume of $\mathrm{ZrO}_{2}\left(\mathrm{Vm}\left(\mathrm{ZrO}_{2}\right) \sim 1.56 \mathrm{Vm}(\mathrm{Zr})\right)$, compressive stresses appear in the oxide near the interface. This may temporarily and locally stabilize the tetragonal- $\mathrm{ZrO}_{2}$ over the monoclinic- $\mathrm{ZrO}_{2}$ at certain temperatures, especially below $1300 \mathrm{~K}$. Therefore, when the oxidation goes on, the stresses relieve and a $\mathrm{ZrO}_{2}$ allotropic phase change may occur, leading to the destabilisation and the cracking of this oxide layer. Such a cracked and porous layer is not protective anymore, and the oxidation kinetics of $\mathrm{Zr}$-based claddings changes to linear or even accelerated $(\mathrm{n}<1)$ : it is called 'breakaway'. [2, 5, 8, 10, 19]

For instance, the oxidation under pure steam of the $1 \mathrm{~cm}$-long ZIRLO® cladding samples is different at $1250 \mathrm{~K}$ compared to $1350 \mathrm{~K}$, both in terms of kinetics and of $\mathrm{ZrO}_{2}$ characteristics, as shown on Figure 2.

\section{SMG (g.m-2)}
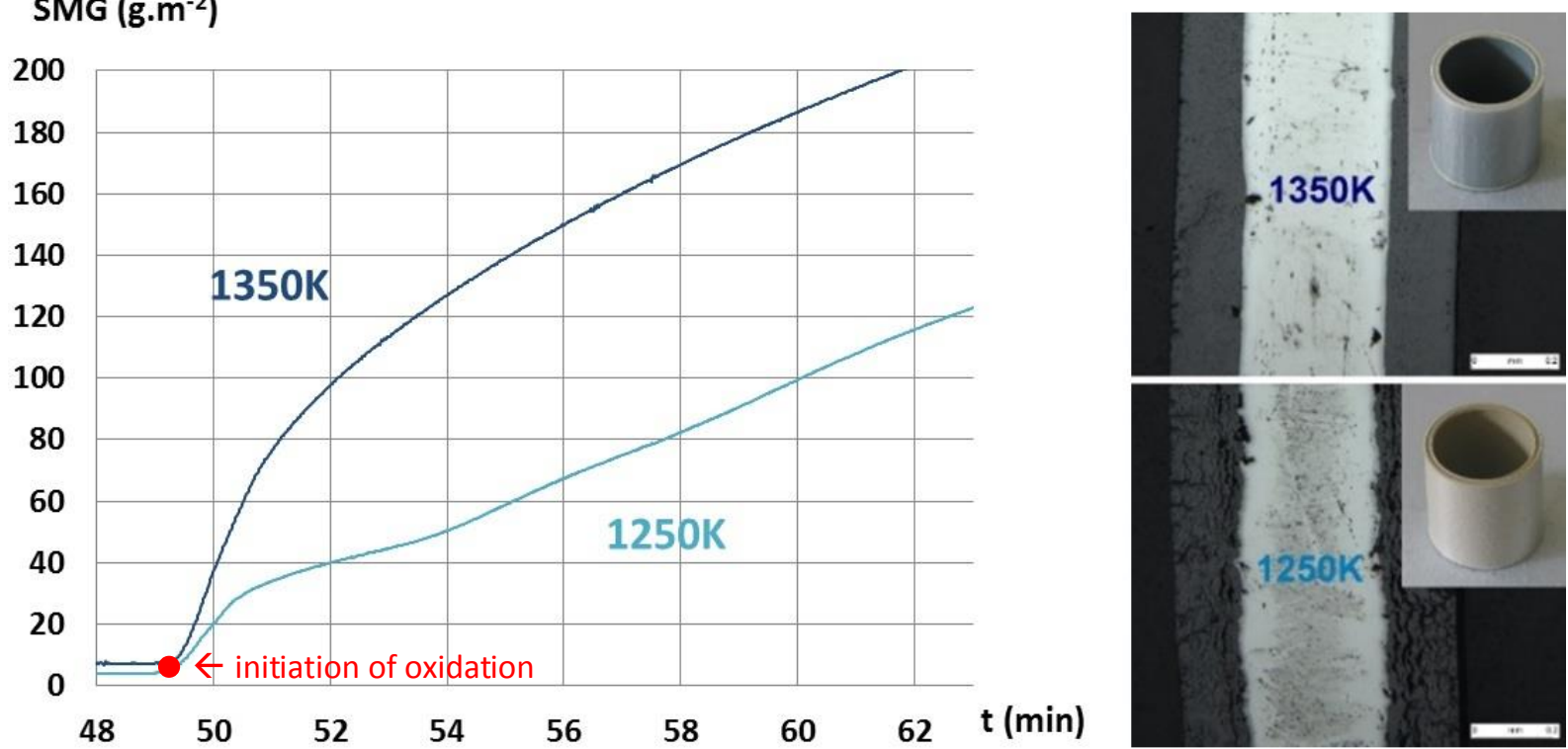

Figure 2: Mass gain kinetics (left) and micrographs with photographs (right) of ZIRLO® cladding samples oxidized under pure steam at 1250 and $1350 \mathrm{~K}$ until a final mass gain around $15 \mathrm{wt} \%\left(\mathrm{SMG} \sim 270 \mathrm{~g} \cdot \mathrm{m}^{-2}\right.$ ) 
The oxidation kinetics at $1350 \mathrm{~K}$ is parabolic ( $\mathrm{n} 2.2)$ and does not exhibit any transition, whereas the one at $1250 \mathrm{~K}$ is first parabolic-cubic $(\mathrm{n} \sim 2.6)$ and then becomes linear ( $\mathrm{n}$ 1.3) after a kinetic transition occurring after around $4 \mathrm{~min}$. This 'breakaway' corresponds to a global cracking of the initially dense $\mathrm{ZrO}_{2}$ layer, as shown on the micrographs: the zirconia layer obtained at $1250 \mathrm{~K}$ seems to be much more cracked and porous than the one formed at $1350 \mathrm{~K}$. However, it is worth noticing that due to the additional $100 \mathrm{~K}$ and despite a denser and more protective oxide layer, the ZIRLO ${ }^{\circledR}$ cladding sample oxidized at $1350 \mathrm{~K}$ reached the final SMG $\left(\sim 270\right.$ g.m $\left.{ }^{-2}\right) 20$ min earlier than the one oxidized at $1250 \mathrm{~K}(\sim 24 \mathrm{~min}$ vs $\sim 44 \mathrm{~min})$. This shows the high temperature dependence of the $\mathrm{Zr}$-based cladding oxidation process.

Below $1200 \mathrm{~K}$ (at 1100 and $1150 \mathrm{~K}$ ), the oxidation kinetics was slow and cubic (n 2.9 at $1150 \mathrm{~K}$ ), no 'breakaway' was observed within test durations, and the oxide layers are globally dense, slightly cracked. At $1200 \mathrm{~K}$, the kinetics was similar to $1250 \mathrm{~K}$ with a 'breakaway' transition from cubic to linear, and the zirconia layer is highly porous and cracked. Above $1250 \mathrm{~K}$ (at 1300, 1450 and $1500 \mathrm{~K}$ ), the oxidation kinetics was similar to $1350 \mathrm{~K}$ with fast and parabolic kinetics ( $\mathrm{n} 2.1$ at $1450 \mathrm{~K}$ ) without 'breakaway', and the $\mathrm{ZrO}_{2}$ layers are fully dense.

\subsection{Phenomenology and results in the air-steam mixture}

During a potential SA sequence, the heat from oxidation by steam of $\mathrm{Zr}$-based claddings adds up to the decay heat. A high temperature increase can then lead core materials to melt and to relocate down to the vessel lower head. If the vessel fails and induces air ingress into the reactor, oxygen and nitrogen both react with $\mathrm{Zr}$-based claddings, causing not only oxidation of $\mathrm{Zr}$ but also formation and oxidation of $\mathrm{Zr}$ nitride $\mathrm{ZrN}$, mainly according to Eq. $(4,5,6)$ as follow:

$$
\begin{aligned}
& \mathrm{Zr}(s)+\mathrm{O}_{2}(g) \stackrel{\Delta \mathrm{H}=-110 \mathrm{~K} J . m o l^{-1}}{\longrightarrow} \mathrm{ZrO}_{2}(s) \\
& \mathrm{Zr}(s)+\frac{1}{2} \mathrm{~N}_{2}(g) \stackrel{\Delta \mathrm{H}=-370 \mathrm{~kJ} . \mathrm{mol}^{-1}}{\longrightarrow} \mathrm{ZrN}(s) \\
& \mathrm{ZrN}(s)+\mathrm{O}_{2}(g) \stackrel{\Delta \mathrm{H}=-730 \mathrm{~kJ} \cdot \mathrm{mol} l^{-1}}{\longrightarrow} \mathrm{ZrO}_{2}(s)+\frac{1}{2} N_{2}(g)
\end{aligned}
$$

Due to a higher enthalpy of reaction, Eq. (4) is favoured, so that Eq. (5) takes place only in case of oxygen starvation (e.g. inside cracks) and Eq. (6) takes place as soon as oxygen is available again. These exothermic reactions are detrimental for two main reasons: additional heat production and zirconia layer destabilization. Indeed, due to different molar volumes of the involved phases $\left(\mathrm{Zr}, \mathrm{ZrO}_{2}, \mathrm{ZrN}\right)$, these coupled and self-sustained chemical reactions strongly destabilise the growing zirconia layers and enhance their cracking. Consequently, as shown on Figure 3, the presence of air, and especially nitrogen, amplifies the 'breakaway' effect and/or enhances the reaction kinetics, because of more deteriorated Zr-based cladding samples $[2,3,4,5,9,10]$. 

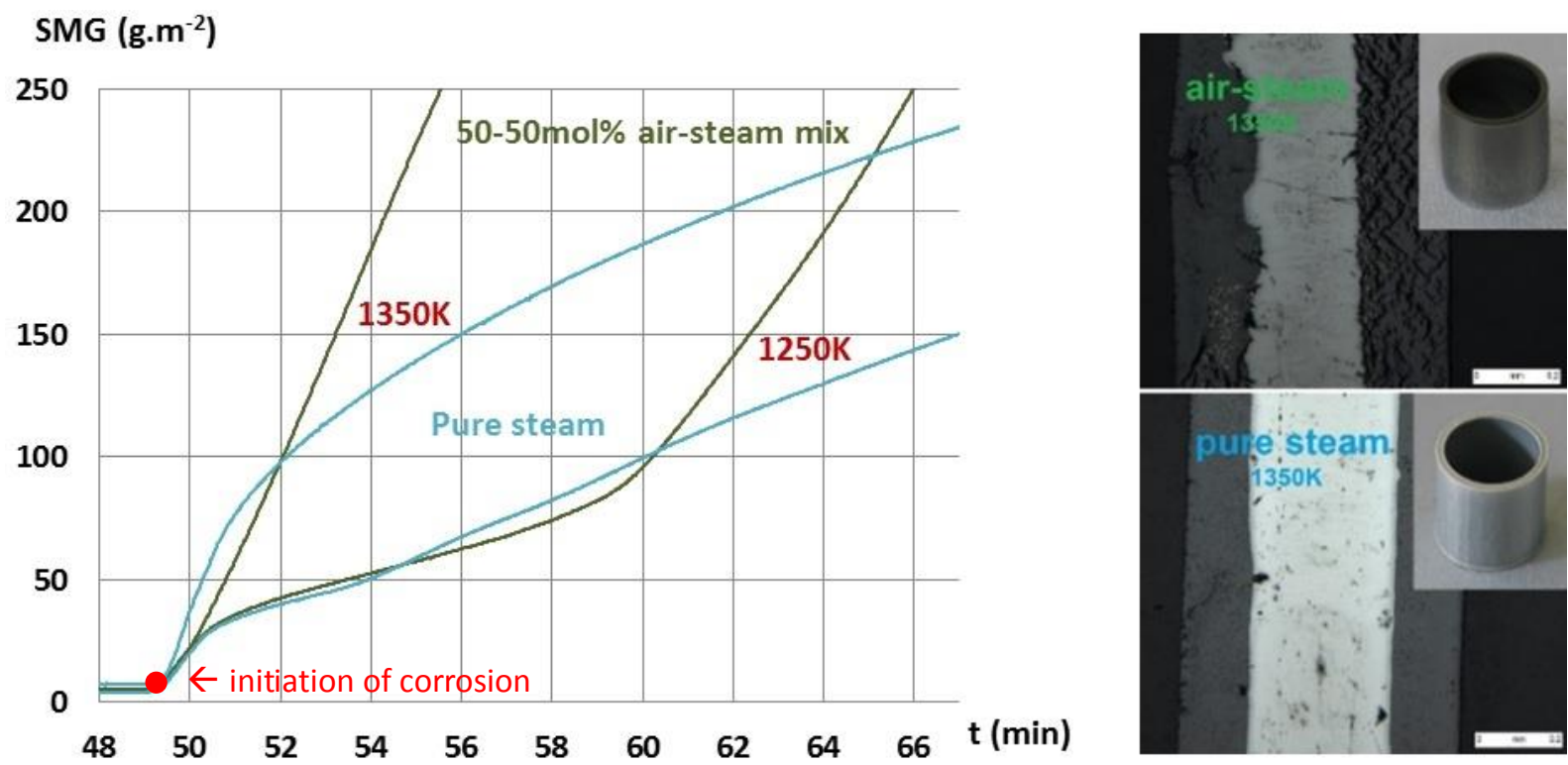

Figure 3: Mass gain kinetics (left) and micrographs with photographs (right) of ZIRLO® cladding samples corroded in pure steam (blue) and air-steam mix (green) at 1250 and $1350 \mathrm{~K}$ until a final SMG around 270 g.m ${ }^{-2}$

The reaction at $1250 \mathrm{~K}$ in the $50-50 \mathrm{~mol} \%$ air-steam mixture exhibits a two-step kinetics as in pure steam: it starts parabolic $(\mathrm{n} \sim 2.3)$ and it becomes linear-accelerated $(\mathrm{n} \sim 0.8)$ after a transition due to the sudden cracking of the zirconia layer. However, this 'breakaway' is much stronger and faster than in pure steam, as illustrated with the graph and with the lower value of $\mathrm{n}$ during the second step $(\sim 0.8$, vs $\sim 1.3$ in pure steam). Similarly, the reaction at $1350 \mathrm{~K}$ in the air-steam mix exhibits a one-step kinetics as in pure steam. However, the value of $\mathrm{n}(\sim 0.9)$ indicates that compared to steam $(\sim 2.2)$ it is rather linear than parabolic, and that the growing zirconia layer is not protective. According to the micrographs, this non-protectiveness is due to cracks and pores which appear only if nitrogen (from air) is present: indeed, by looking at the zirconia layer, one can see small golden areas, near the metal-oxide interface, which are nitride $\mathrm{ZrN}$ particles.

In the air-steam mixture, the reaction kinetics is slightly more accelerated at $1250 \mathrm{~K}$ ( $\mathrm{n} \sim 0.8$ ) after the 'breakaway' than at $1350 \mathrm{~K}(\mathrm{n} \sim 0.9)$. However, due to the delay induced by the first slow parabolic period ( $10 \mathrm{~min})$, the ZIRLO® cladding sample submitted to $1250 \mathrm{~K}$ reached the final SMG $\left(\sim 270\right.$ g. $\left.\mathrm{m}^{-2}\right) 11$ min later than the one at $1350 \mathrm{~K}(\sim 18 \mathrm{~min}$ vs $\sim 7 \mathrm{~min})$.

Below $1300 \mathrm{~K}$ (at 1100, 1150, 1200, 1250 and $1300 \mathrm{~K}$ ), a 'breakaway' transition from (sub-)parabolic to linear or slightly accelerated kinetics was observed. Above $1350 \mathrm{~K}$ (1350, 1450 and $1500 \mathrm{~K})$, no 'breakaway' was observed and the reaction kinetics was linear $(\mathrm{n} \sim 1)$ from the beginning. Contrary to pure steam, micrographs of all ZIRLO® cladding samples submitted to air-steam exhibit cracked and porous zirconia layers, for all temperatures. Like in pure steam, this porosity cannot be quantified by micrographs, but a specific porosimetry study by $\mathrm{Hg}$ intrusion can provide quantitative information about it. 


\section{POROSIMETRY OF ISOTHERMALLY CORRODED ZIRLO® CLADDINGS}

In order to quantify the porosity and so the degradation of ZIRLO ${ }^{\circledR}$ cladding samples, the porosimetry results are presented and analysed with regard to: the influence of oxidizing conditions (4.1) and the impact of the 'breakaway' (4.2), both on the porosity of corroded samples.

\subsection{Influence of oxidizing conditions}

The more intuitive data provided by the twofold porosimeter, is the accessible porosity (POR, in vol\%) which is the intruded $\mathrm{Hg}$ volume relative to the total sample volume. By plotting this as a function of the temperature, one can confirm and quantify some observations and conclusions deduced from various $\mathrm{Zr}$ corrosion experiments (of the present study and of many previous ones $[2,3,4,5,8,9,10,19])$, as illustrated on Figure 4.

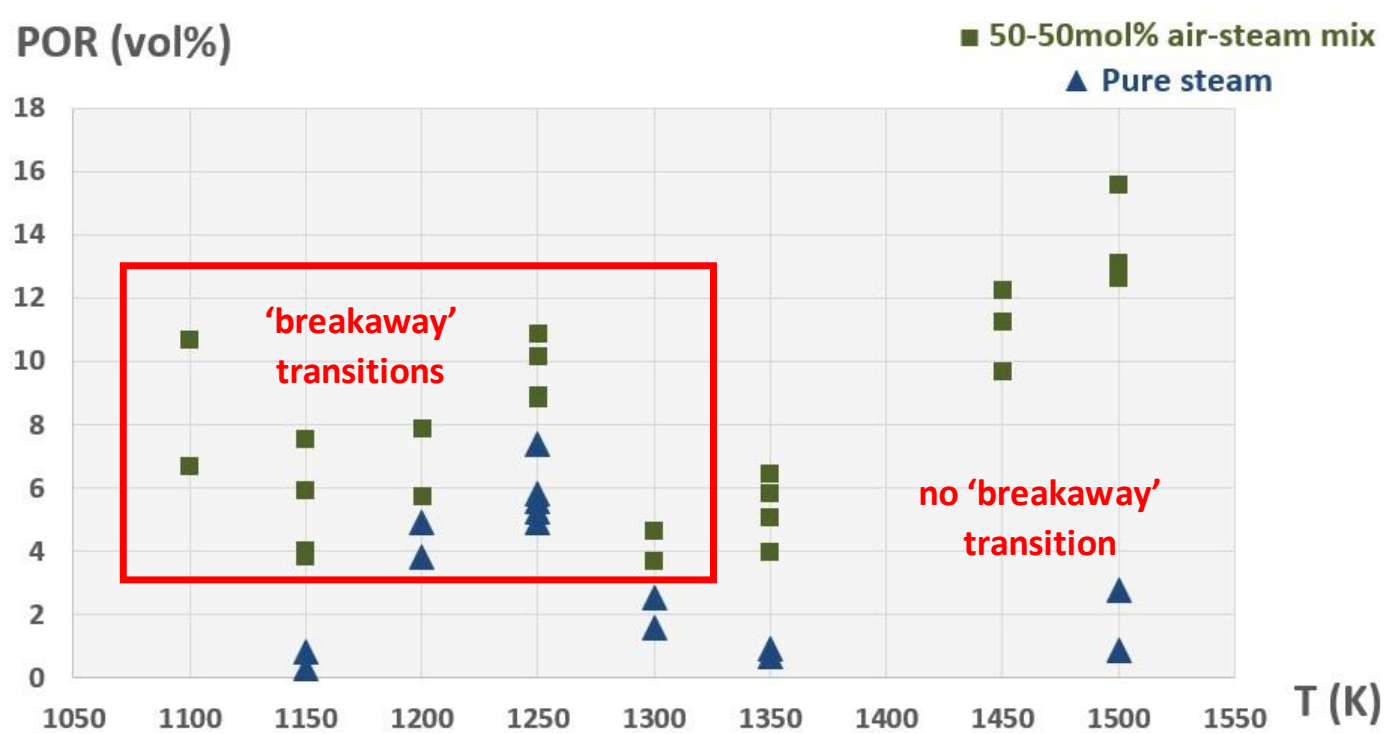

Figure 4: POR (vol\%) of ZIRLO® samples corroded in the 50-50mol\% air-steam mix (green) or steam (blue), until SMG higher than 210 g.m ${ }^{-2}$, except for pure steam at 1150 and $1200 \mathrm{~K}$ : between 120 and 160 g.m.2

First, one can see that all ZIRLO ${ }^{\circledR}$ cladding samples corroded in the air-steam mixture exhibit a significant porous volume fraction, between 4 vol\% (at 1150, 1300 and $1350 \mathrm{~K}$ ) and $16 \mathrm{vol} \%$ (at $1500 \mathrm{~K}$ ), even if no 'breakaway' effects were observed (at 1350, 1450 and 1500 $\mathrm{K})$. On the contrary, among the samples oxidized under pure steam, some have a significant POR between 4 and 7 vol\% at 1200 and $1250 \mathrm{~K}$, whereas others exhibit a low porosity between 0 and 2.5 vol\% at other temperatures. Since 'breakaway' transitions and oxide cracking were recorded and observed only at 1200 and $1250 \mathrm{~K}$, the link between 'breakaway' effects and significant porosity is clear in pure steam. To summarize this, a ZIRLO® cladding sample has a significant porous volume fraction if it was corroded in the air-steam mixture and/or if its oxidation kinetics exhibited a 'breakaway' transition.

Finally, one can remark that several ZIRLO® cladding samples oxidized in the same conditions (same temperature, atmosphere and duration) do not exhibit exactly similar porous 
volume fractions. According to the graph, this variability of the porosity data is around 4 vol\% at maximum: for air-steam at 1100 and $1150 \mathrm{~K}$, conditions in which strong 'breakaway' effects were observed. Indeed, this variability is due not only to uncertainties of porosimetry measurements (estimated around $1 \mathrm{vol} \%$ ) but also and above all to the variability of corrosion experiments which is particularly significant in case of 'breakaway' effects: similar cladding samples did not oxidize with exactly the same kinetics.

\subsection{Impact of the 'breakaway'}

To confirm the impact of 'breakaway' transitions on the porous volume fraction of oxidized ZIRLO® samples, one can focus on experimental conditions in which 'breakaway' took place (from 1100 to $1300 \mathrm{~K}$ in air-steam mix, plus at 1200 and $1250 \mathrm{~K}$ in pure steam) and add the porosity data of the samples corroded only before the 'breakaway' occurs, as done in Figure 5.

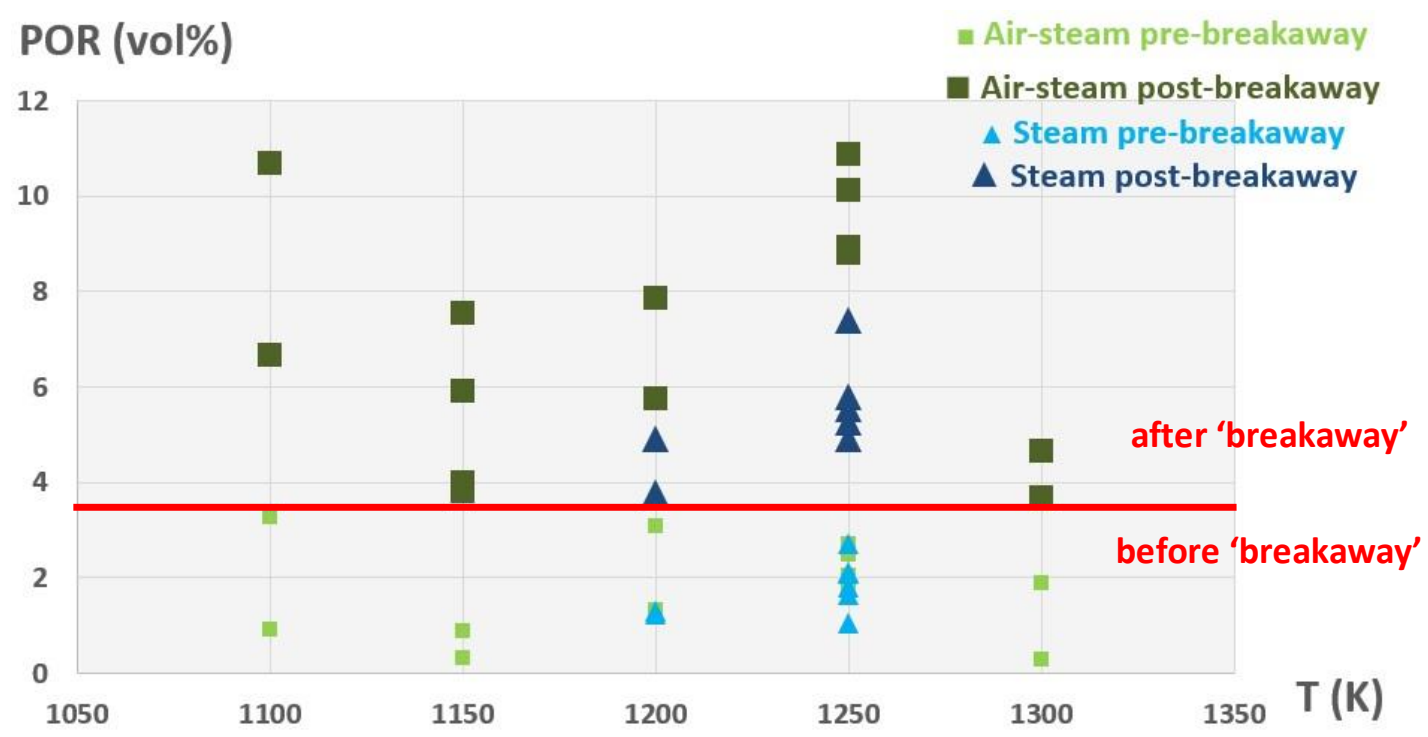

Figure 5: POR (vol\%) of ZIRLO® samples corroded in the 50-50mol\% air-steam mix (green) or steam (blue), until after the 'breakaway' transition $\left(140<\mathrm{SMG}<330\right.$ g.m $\left.{ }^{-2}\right)$ or before it $\left(30<\mathrm{SMG}<130\right.$ g.m $\left.{ }^{-2}\right)$

For ZIRLO® cladding samples oxidized under pure steam at 1200 or $1250 \mathrm{~K}$, the porous volume fraction is significantly higher after $(\sim 5$ vol $\%)$ than before $(\sim 2$ vol $\%)$ the 'breakaway' transition. For samples submitted to $50-50 \mathrm{~mol} \%$ air-steam mix, the trend is similar. Indeed, POR never exceeds 3.3 vol\% before the 'breakaway' transition and always exceeds 3.7 vol\% after it. Moreover, at all temperatures tested, POR is systematically at least 1 vol\% higher after than before the 'breakaway'. Additionally, it is worth noticing that $1250 \mathrm{~K}$ is the temperature at which the 'breakaway' transition seems to induce the highest porosity increase: from $\sim 2$ up to $\sim 5.5$ vol\% under pure steam, and from $\sim 2.5$ up to $\sim 9.5 \mathrm{vol} \%$ in air-steam.

It is also interesting to focus only on the two temperatures at which 'breakaway' transitions were observed both under pure steam and in the air-steam mixture: 1200 and 1250 K, as shown on Figure 6 which plots POR (vol\%) as a function of SMG $\left(\mathrm{g} \cdot \mathrm{m}^{-2}\right)$. 


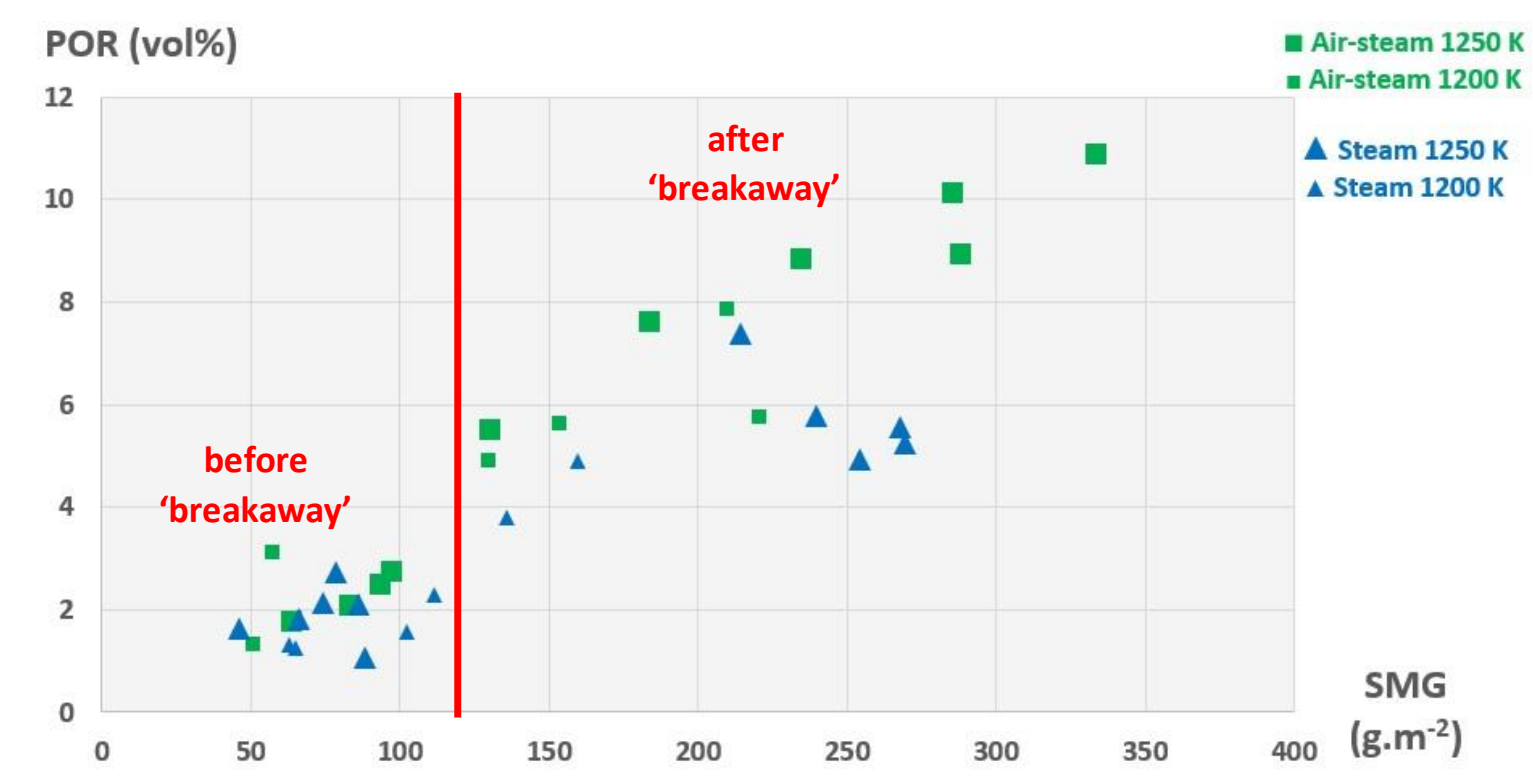

Figure 6: POR (vol\%) of ZIRLO® samples corroded under pure steam or in the $50-50 \mathrm{~mol} \%$ air-steam mixture, at 1200 or $1250 \mathrm{~K}$, as a function of the $\operatorname{SMG}\left(\mathrm{g} \cdot \mathrm{m}^{-2}\right)$

At both temperatures, the sample POR remains slightly higher in the air-steam mix than under pure steam. In each of these four oxidizing conditions, POR seems to be approximately proportional to SMG during the corrosion of ZIRLO® cladding samples.

\section{POROSITY INCREASE RATES}

In order to better model and simulate in SA codes the corrosion of $\mathrm{Zr}$-based claddings and the degradation of their zirconia layers, the porosimetry results are now used to determine porosity correlations (5.1), and to deduce and validate porosity increase rates (5.2), depending on the experimental conditions.

\subsection{Determination of porosity correlations}

To determine porosity increase rates, for each experimental condition (temperature and atmosphere), it is first necessary to identify isothermal porosity correlations by using graphs which exhibit POR as a function of SMG.

Under pure steam, as shown on Figure 4 and confirmed by Figure 7, only the two temperatures involving 'breakaway' phenomena, 1200 and $1250 \mathrm{~K}$, led to samples with significant porosity values above 3 vol\%. 


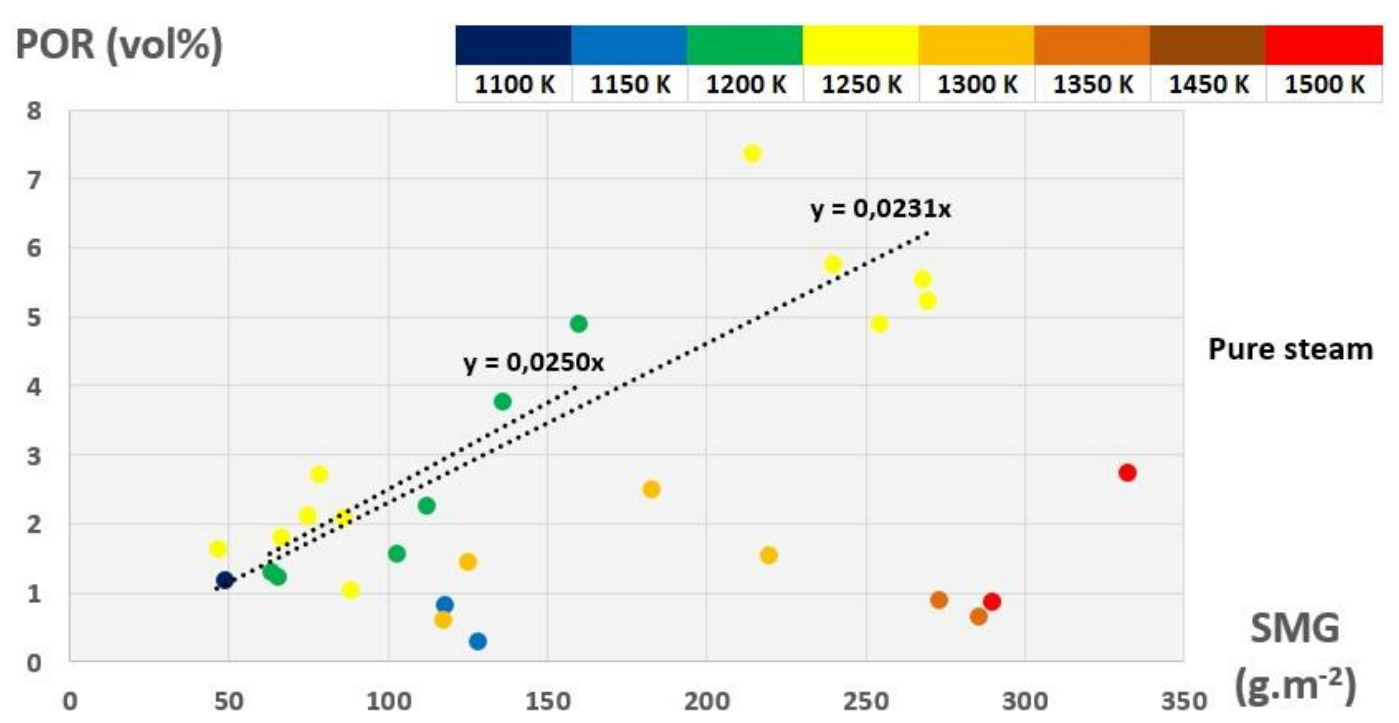

Figure 7: POR (vol\%) of ZIRLO® cladding samples oxidized under pure steam at different temperatures, as a function of the SMG $\left(\mathrm{g} \cdot \mathrm{m}^{-2}\right)$

Moreover, as suggested on Figure 6, one can see on Figure 7 that linear regressions indicate approximately the same porosity correlation for 1200 and $1250 \mathrm{~K}$ in pure steam:

$$
0.02 * \operatorname{SMG}\left(\mathrm{g} \cdot \mathrm{m}^{-2}\right)<\operatorname{POR}(\text { vol\% })<0.03 * \operatorname{SMG}\left(\mathrm{g} \cdot \mathrm{m}^{-2}\right)
$$

For all other tested temperatures $(1100,1150,1300,1350,1450$ and $1500 \mathrm{~K})$, the following correlation could be considered in pure steam:

$$
\operatorname{POR}(\text { vol\% })=0
$$

In the 50-50mol\% air-steam mixture, as shown on Figure 4 and confirmed by Figure 8 , every temperature led to the cracking of $\mathrm{ZrO}_{2}$ layers (even without 'breakaway' kinetic transitions) and to significant porosity values above 4 vol\%.

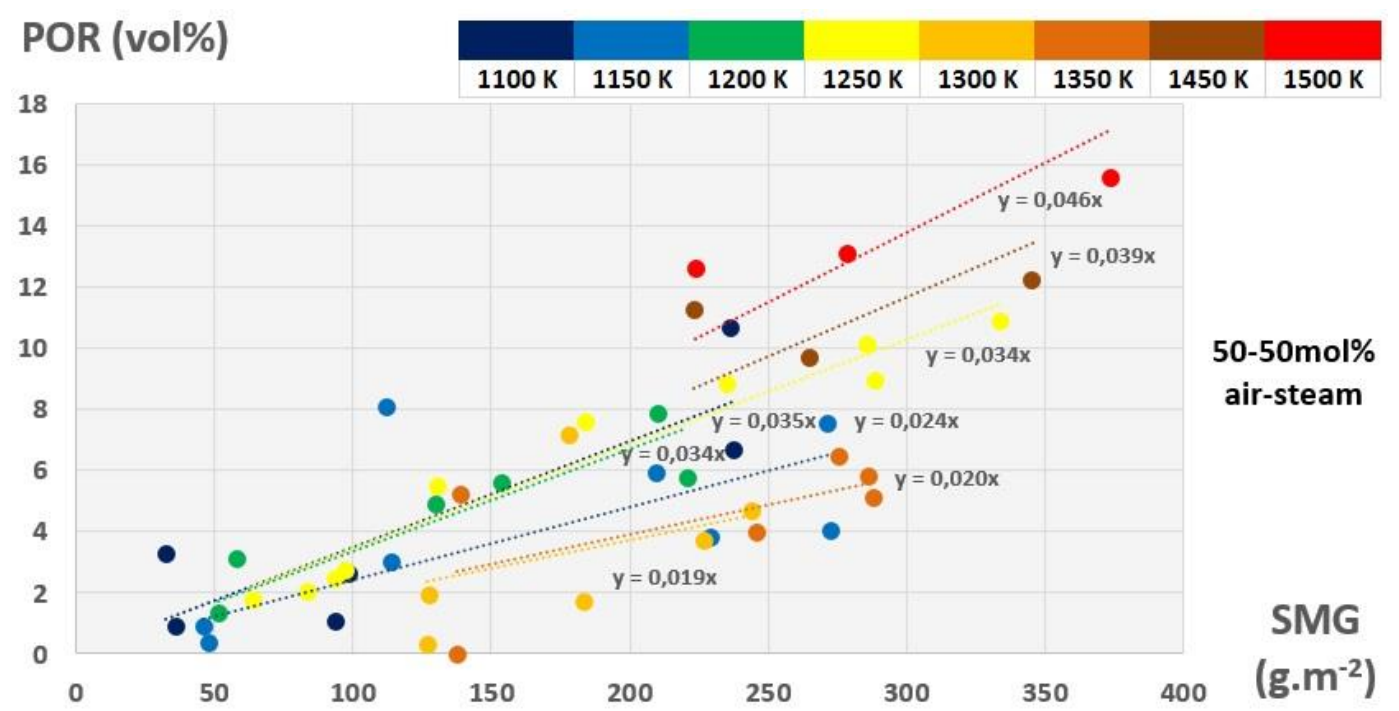

Figure 8: POR (vol\%) of ZIRLO® cladding samples corroded in the 50-50mol\% air-steam mix at different temperatures, as a function of the SMG $\left(\mathrm{g} \cdot \mathrm{m}^{-2}\right)$ 
From this graph, three correlations can be distinguished for the corrosion of ZIRLO ${ }^{\circledR}$ cladding samples in the air-steam mix. Indeed, from the highest down to the lowest temperatures, one can see:

$$
\begin{array}{ll}
0.035 * S M G<P O R<0.045 * S M G & \text { At } 1450 \text { and } 1500 \mathrm{~K} . \\
0.015 * S M G<P O R<0.025 * S M G & \text { At } 1300 \text { and } 1350 \mathrm{~K} . \\
0.025 * S M G<P O R<0.040 * S M G & \text { At } 1100,1150,1200 \text { and } 1250 \mathrm{~K} .
\end{array}
$$

\subsection{Determination and validation of porosity increase rates}

\begin{tabular}{|c|c|c|c|c|c|}
\hline $\mathrm{T}(\mathrm{K})$ & 0 & 175 & 275 & 25 & 00 \\
\hline Steam & $\mathrm{POR}=0$ & $\begin{array}{c}P O R= \\
0.025^{*} \text { SMG }\end{array}$ & & $P O R=0$ & \\
\hline Air-steam & $P O R=$ & $030 *$ SMG & $\begin{array}{c}\text { POR }= \\
0.020^{*} \text { SMG }\end{array}$ & $\begin{array}{c}\text { POR }= \\
0.020^{*} \text { SMG }\end{array}$ & $\begin{array}{c}\text { POR }= \\
0.040^{*} \text { SMG }\end{array}$ \\
\hline
\end{tabular}

Figure 9 gathers the isothermal porosity correlations, found above, in several temperature domains and for the two tested atmospheres.

Figure 9: Summary of porosity correlations deduced from porosimetry results of isothermally corroded ZIRLO® cladding samples (caption: darker areas = 'breakaway’ occurred, and hatched areas = zirconia layer cracked)

However, these isothermal porosity correlations could not be used in real time in SA codes to model the degradation of Zr-based claddings and to simulate the influence of their porosity on their corrosion process. For this, it is necessary to determine porosity increase

\begin{tabular}{|c|c|c|c|c|c|}
\hline $\mathrm{T}(\mathrm{K})$ & 0 & & 1275 & 1325 & 1400 \\
\hline Steam & $\mathrm{dP} / \mathrm{dt}=0$ & $\begin{array}{l}\mathrm{dP} / \mathrm{dt}= \\
0.025^{*} \\
\mathrm{dM} / \mathrm{dt}\end{array}$ & \multicolumn{3}{|c|}{$\mathrm{dP} / \mathrm{dt}=0$} \\
\hline Air-steam & \multicolumn{2}{|c|}{$\mathrm{dP} / \mathrm{dt}=0.030^{*} \mathrm{dM} / \mathrm{dt}$} & $\begin{array}{l}d P / d t= \\
0.020^{*} \\
d M / d t\end{array}$ & $\begin{array}{l}\mathrm{dP} / \mathrm{dt}= \\
0.020^{*} \\
\mathrm{dM} / \mathrm{dt}\end{array}$ & $\begin{array}{l}\mathrm{dP} / \mathrm{dt}= \\
0.040^{*} \\
\mathrm{dM} / \mathrm{dt}\end{array}$ \\
\hline
\end{tabular}
rates by deriving the previous isothermal correlations versus time, as summarized in Figure 10.

Figure 10: Summary of porosity increase rates derived from isothermal porosity correlations (same caption as for Figure 9, plus $\mathrm{P}=\mathrm{POR}$ and $\mathrm{M}=\mathrm{SMG}$ )

Before implementing these porosity increase rates in SA codes, it is important to validate them. For this, porosimetry measurements of ZIRLO® cladding samples corroded in transient (non-isothermal) conditions must be achieved. Therefore, three transient corrosion 
experiments, with temperature increasing $50 \mathrm{~K} \cdot \mathrm{min}^{-1}$ from 1100 up to $1500 \mathrm{~K}$, were performed: 2 under pure steam produced samples with POR $=0.33$ and 1.22 vol\% (SMG 110 g.m ${ }^{-2}$ ), and 1 in the air-steam mix led to a cladding sample with POR $=1.63$ vol\% (SMG $\sim 140$ g.m $\mathrm{m}^{-2}$ ).

During such a transient, the ZIRLO® samples should reach, according to calculations using the porosity increase rates, $0.33 \mathrm{vol} \%$ under pure steam and $3.38 \mathrm{vol} \%$ in the air-steam mix. The orders of magnitude are right and the logic is respected (higher POR in air-steam than in pure steam), but the three POR values are too low (compared to measurement uncertainties) to make definitive conclusions.

Indeed, it would be worth performing additional transient tests, at lower temperature increase rates and/or through larger temperature domains, to get more oxidized (SMG 200$300 \mathrm{~g} . \mathrm{m}^{-2}$ ) and so more porous (POR 4-16 vol\%) cladding samples.

\section{CONCLUSIONS, DISCUSSIONS, PERSPECTIVES}

To quantify the degradation state of Zr-based claddings during nuclear SA sequences, a series of two-step experiments was conducted. First, 10mm-long ZIRLO® cladding tube samples were isothermally oxidized in nuclear SA conditions: either under pure steam or in a $50-50 \mathrm{~mol} \%$ air-steam mix, at temperatures from 1100 up to $1500 \mathrm{~K}$, and for different durations. Second, pioneering porosimetry measurements by $\mathrm{Hg}$ intrusion were realized on such corroded samples. In corrosion tests, 'breakaway' effects and transitions from (sub)parabolic to linear or accelerated kinetics were observed for samples submitted either to the air-steam mix at 1100, 1150, 1200, 1250 and $1300 \mathrm{~K}$, or to pure steam at 1200 and $1250 \mathrm{~K}$. The porous volume fraction is significant for all these corroded samples (between 4 and 11 vol\%), and also for those submitted to air-steam beyond $1300 \mathrm{~K}$ (between 4 and 16 vol\%). Indeed, the nitrogen reacts with the zirconium of claddings, through formation and oxidation of $\mathrm{ZrN}$ particles, destabilizing zirconia layers and making them porous. Moreover, the cladding samples oxidized only before the 'breakaway' exhibit low porous volume fractions (below $3.3 \mathrm{vol} \%$ ). This difference in porosity is particularly high at $1250 \mathrm{~K}$ in the $50-50 \mathrm{~mol} \%$ air-steam mixture (from $\sim 2.5$ up to $\sim 9.5$ vol\%), because of strong 'breakaway' effects. More generally, in most of tested conditions, the porous volume fraction of ZIRLO ${ }^{\circ}$ cladding samples seems to rise during their corrosion process, and so POR seems to be proportional to SMG. Therefore, it was possible to determine porosity correlations, and then by derivation versus time, to obtain porosity increase rates for each experimental condition.

Several parameters, which may influence the cladding corrosion and the zirconia layer degradation, have not been investigated in this study. First, it is well known that all $\mathrm{Zr}$ alloys do not react at the same rate and degrade in the way $[3,5,10]$ : for instance, Zircaloy-4, or M5® from AREVA could be studied because they are widely used in PWRs, but also other commercial or non-commercial $\mathrm{Zr}$ alloys could be investigated too, such as Optimized ZIRLO ${ }^{\mathrm{TM}}$, E110, E110G, or Duplex-D4. Second, the temperature is also known as a major influencing parameter, and values higher than $1500 \mathrm{~K}$ could be tested by using another experimental setup in order to reduce the impact of extrapolations. Third, the existence of a pre-oxide layer 
grown in operational conditions can also influence the subsequent cladding behavior in SA conditions: it can be either detrimental or beneficial depending on its thickness, its protectiveness and the temperature $[3,4,9,10]$. Fourth, modifications of the gas flow rate result in different partial pressures, which may influence the cladding corrosion process by inducing (lower rates) or reducing (higher rates) gas starvation conditions. Fifth, the nitrogen proportion in the gas mixture could only have a limited impact on the corrosion process: indeed, from $1-5$ up to $80-90 \mathrm{~mol} \%$ (40 mol\% in our study), it is shown the cladding degradation remains quite similar $[9,20]$.

The porosity increase rates could then be implemented in SA codes to simulate in real time, during the corrosion process, the evolution of the Zr-based cladding porosity and its impact on the cladding behavior during SA sequences. In specific conditions, such as air ingress into the vessel (with corium reflooding in the reactor pit) or core reflooding, the cladding porosity becomes significant and could ease and/or enhance the corrosion process and so the hydrogen production.

\section{ACKNOWLEDGMENTS}

We thank the people, from the Institute for Applied Materials at KIT, who performed or helped performing some of the experiments: Yunxiao Wu, Ulrike Stegmaier, Petra Severloh, Margarette Offermann and Joachim Binder.

\section{REFERENCES}

[1] Powers, D. A., Kmetyk, L. N. and Schmidt, R. C., "A review of the technical issues of air ingression during severe reactor accidents", Report NUREG/CR-6218 SAND940731, Sandia National Laboratories, 1994.

[2] Beuzet, E., "Modélisation des conséquences d'une entrée d'air en cuve sur le calcul du Terme Source en accident grave", PhD thesis, Université Paris-XI, 2010.

[3] Duriez, C., Dupont, T., Schmet, B. and Enoch, F., "Zircaloy-4 and M5® high temperature oxidation and nitriding in air", Journal of Nuclear Materials, Vol. 380, 2008, pp. 30-45.

[4] Duriez, C., Steinbrück, M., Ohai, D., Meleg, T., Birchley, J. and Haste, T., "Separateeffect tests on zirconium cladding degradation in air ingress situations", Nuclear Engineering and Design, Vol. 239, 2009, pp. 244-253.

[5] Steinbrück, M., Große, M., Sepold, L. and Stuckert, J., "Synopsis and outcome of the QUENCH experimental program", Nuclear Engineering and Design, Vol. 240, 2010, pp. 1714-1727.

[6] Karlsruhe Institute of Technology, QUENCH programme, QUENCH test matrix, viewed in February 2016, http://quench.forschung.kit.edu/24.php

[7] Steinbrück, M., "Analysis of hydrogen production in QUENCH bundle tests", Report FZKA 6968, FZK, 2004. 
[8] Steinbrück, M., Vér, N. and Große, M., "Oxidation of advanced zirconium cladding alloys in steam at temperatures in the range of $600-1200^{\circ} \mathrm{C}$ ", Oxidation of Metals, Vol. 76, 2011, pp. 215-232.

[9] Steinbrïck, M., "Prototypical experiments relating to air oxidation of Zircaloy-4 at high temperatures", Journal of Nuclear Materials, Vol. 392, 2009, pp. 531-544.

[10] Steinbrück, M. and Große, M., "Deviations from parabolic kinetics during oxidation of zirconium alloys", ASTM Special Technical Publication, STP 1543, 2015, pp. 9791001 .

[11] Beuzet, E., Baumgarten, C. and Steinbrück, M., "Modelling of cladding oxidation by air under severe accident conditions with the MAAP4 code", Proc. Int. Conf. WRFPM 2014, Sendai, Japan, September 14-17, 2014, Paper N 100018.

[12] Beuzet, E., Haurais, F., Bals, C., Coindreau, O., Fernandez-Moguel, L., Vasiliev, A. and Park, S., "Cladding oxidation during air ingress. Part II: Synthesis of modelling results", Proc. Int. Conf. ERMSAR 2015, Marseille, France, March 24-26, 2015, Paper N²015038.

[13] Haurais, F., Beuzet, E., Steinbrück, M., Ambard, A. and Simoni, E., "Porosimetry of zirconia scales formed during oxidation of $\mathrm{Zr}$-based fuel claddings in steam and airsteam mix at high temperatures", Proc. Int. Conf. ERMSAR 2015, Marseille, France, March 24-26, 2015, Poster $N^{\circ} 2015-086$.

[14] Haurais, F., Beuzet, E., Steinbrïck, M., Wu, Y., Ambard, A., Simoni, E. and Torkhani, M., "Porosimetry of $\mathrm{ZrO}_{2}$ scales formed during oxidation of $\mathrm{Zr}$-based fuel claddings in nuclear Severe Accidents conditions", Proc. Int. Conf. NENE 2015, Portoroz, Slovenia, September 14-17, 2015, Paper N805.

[15] Webb, P. A., "An introduction to the physical characterization of materials by mercury intrusion porosimetry with emphasis on reduction and presentation of experimental data", Report, Micromeritics Instrument Corp., 2001.

[16] France Scientifique, Produits, Caractérisation des poudres, Porosimètre au mercure, viewed in February 2016, http://www.france-scientifique.fr/produits/caracterisationsdes-poudres/porosimetre-au-mercure/

[17] "SOL.I.D Software - User Guide. Part 4: Calculations in Mercury Porosimetry", Report, Thermo Scientific, 2005.

[18] "Thermo Scientific Pascal series mercury porosimeters - Product specifications", Report, Thermo Scientific, 2009.

[19] Godlewski, J., "Oxydation d'alliages de zirconium en vapeur d'eau : influence de la zircone tétragonale sur le mécanisme de croissance de l'oxyde", $\mathrm{PhD}$ thesis, Université de technologie de Compiègne, 1990.

[20] Steinbrück, M. and Schaffer, S., "High-temperature oxidation of Zircaloy-4 in OxygenNitrogen mixtures", Oxidation of Metals, Vol. 85, 2016, pp. 245-262. 